\title{
Role of lymph node dissection in radical cystectomy
}

\author{
KEYI WANG ${ }^{1}$, HENG SHI ${ }^{1, *}$, WEIPU MAO ${ }^{1 *}$, LEI YIN ${ }^{1}$, GUANGCHUN WANG $^{1}$, \\ DONGLAI FAN ${ }^{1}$, JINBO XIE ${ }^{1}$, WEIYI LI ${ }^{1}$ and BO PENG ${ }^{1,3}$ \\ ${ }^{1}$ Department of Urology, Shanghai Tenth People's Hospital, School of Medicine, Tongji University, Shanghai 200072;
${ }^{2}$ Department of Urology, Shanghai Tenth People's Hospital, Nanjing Medical University, Nanjing, Jiangsu 210011;
${ }^{3}$ Department of Urology, Putuo People's Hospital of Tongji University, Shanghai 200060, P.R. China
}

Received August 30, 2019; Accepted December 20, 2019

DOI: $10.3892 / \mathrm{ol} .2020 .11563$

\begin{abstract}
The number of lymph node dissections (LNDs) is an independent factor influencing the survival time of patients with bladder cancer $(\mathrm{BCa})$ after radical resection $(\mathrm{RC})$. The present study aimed to investigate the association between the number of LNDs and the survival of patients with $\mathrm{BCa}$ at different stages and who underwent RC in the United States of America and China. Records from 17,730 American patients with BCa and 158 Chinese patients with $\mathrm{BCa}$ were collected from the Surveillance, Epidemiology and End Results (SEER) and the Shanghai Tenth People's Hospital (China) databases, respectively. Kaplan-Meier curve and $\chi^{2}$ test were used to determine the overall survival time (OS) of patients with $\mathrm{BCa}$. Cox regression analysis was used to analyze the effects of LND number on OS. Overall, 13,421 (75.7\%) patients were negative for lymph node metastasis (N0) and 4,309 (24.3\%) were positive for lymph node metastasis $(\mathrm{N}+)$ among the 17,730 American patients with BCa. In the group of 158 Chinese patients, 125 (79.1\%) were N0 and 33 (20.9\%) were N+. In the American patients, the median number of dissected nodes was 11.0 [interquartile range $(\mathrm{IQR})=3.0-21.0]$ for $\mathrm{N} 0$ patients and $14.0(\mathrm{IQR}=8.0-23.0)$ for $\mathrm{N}+$ patients. The median number of LNDs was 5.0 (IQR=2.0-7.0) for Chinese N0 patients and 5.0 (IQR=1.5-10.5) for Chinese N+ patients. The number of LNDs may therefore be an independent factor associated with survival in patients who underwent RC. Furthermore, a higher number of LNDs was associated with longer OS in patients with $\mathrm{BCa}$ [American patients, $\geq 13$ nodes vs. $\leq 5$ nodes, hazard ratio $(\mathrm{HR})=0.62,95 \%$ confidence interval $(\mathrm{CI})=0.59-0.65, \mathrm{P}<0.001$; Chinese patients, $\geq 5$ nodes vs. $\leq 1$ node, $\mathrm{HR}=0.27,95 \% \mathrm{CI}=0.12-0.62, \mathrm{P}=0.002]$. The number of LNDs in patients with $\mathrm{BCa}$ and $\mathrm{N}+$ was higher compared with
\end{abstract}

Correspondence to: Professor Bo Peng, Department of Urology, Shanghai Tenth People's Hospital, School of Medicine, Tongji University, 301 Yanchang Road, Jing'an, Shanghai 200072, P.R. China

E-mail: pengbo6908@163.com

*Contributed equally

Key words: bladder cancer, radical cystectomy, lymph node dissection, overall survival, Surveillance, Epidemiology and End Results number of LNDs in patients with BCa and N0 who underwent RC. More extensive LND improved the OS in both the patients from USA and China. Increasing the number of LNDs may therefore be crucial when treating patients with $\mathrm{BCa}$.

\section{Introduction}

Bladder cancer (BCa) is one of the most common type of cancer of the urinary system (1). In USA, $\sim 81,190$ new cases of $\mathrm{BCa}$ were diagnosed in 2018, accounting for $4.7 \%$ of all new cancer cases, and $\sim 17,240 \mathrm{BCa}$-associated mortality cases were reported, accounting for $2.8 \%$ of all mortality cases (2). According to the tumor invasion depth, BCa can be divided into non-muscle invasive bladder cancer (NMIBC) and muscle invasive bladder cancer (MIBC) (3). Furthermore, $\sim 70 \%$ of $\mathrm{BCa}$ cases are NIMBCs, which are characterized by a high-recurrence rate $(30-80 \%)(4,5)$. Surgery is the main treatment for patients with $\mathrm{BCa}$. Transurethral resection of bladder tumors remains the most commonly used treatment for NMIBC (6), whereas radical cystectomy (RC) combined with pelvic lymph node dissection (LND) is currently the main procedure to treat $\operatorname{MIBC}(7,8)$.

Based on a statistical analysis of clinical data, it was reported that increasing the extent of pelvic lymph node clearance might improve the survival rate of patients with $\mathrm{BCa}$ following RC $(9,10)$. Furthermore, a previous study demonstrated that extended LND improves the survival rate of patients with $\mathrm{BCa}$ (11). However, the optimal range of surgical resection and the number of LNDs remain unclear (12-14). The present study aimed therefore to evaluate the appropriate number of LNDs to be performed in patients with BCa.

Following a review of the literature, the majority of studies investigating the impact of LNDs on the survival rate and perioperative results of patients with $\mathrm{BCa}$ treated with $\mathrm{RC}$ were based on data from medical centers in developed countries (15-17). A multicenter prospective study on this issue has been previously conducted in Germany (18). To the best of our knowledge, there are only a few comparative studies of data obtained from two medical centers of different countries. The present study compared data on the degree of LND performed in patients with $\mathrm{BCa}$ who underwent $\mathrm{RC}$ treatment in our medical center with data from USA patients with $\mathrm{BCa}$ who underwent RC, which were collected from the Surveillance, Epidemiology and End Results (SEER) database. 


\section{Materials and methods}

Data source and patients. Data from 17,859 patients with $\mathrm{BCa}$ who underwent RC and pelvic lymphadenectomy between January 2004 and December 2015 were collected from the SEER using the National Cancer Institute's SEER*Stat software version 8.3.5 (19). Bladder malignancies with the ICD-O-3 surgical method site code C670-C679 (seer. cancer.gov/manuals/2018/appendixc.html) were selected. $\mathrm{BCa}$ surgical treatment information was obtained from the RX summary variable (codes 50, 60-64, 70-74 and 80 were defined as RC). The SEER database provides information about patients with cancer, including demographic information, primary tumor location, cancer staging, treatment and survival time, from 18 registries, which covers $\sim 28 \%$ of the American population (19).

The exclusion criteria were as follows: i) Patients with unknown number of lymph nodes; ii) patients with unknown survival time; iii) patients with unknown Tumor-Node-Metastasis (TNM) stage (20); and iv) patients aged under 18 years. A total of 17,730 patients with $\mathrm{BCa}$ were qualified and included in the present study.

A total of 158 patients with $\mathrm{BCa}$ diagnosed at the Shanghai Tenth People's Hospital between January 2016 and December 2018 were included in this study. Patients were followed up until December 2018. The study was approved by the Ethics Committee of Shanghai Tenth People's Hospital of Tongji University, and written informed consent was obtained from the patients or their next of kin if the patient did not have the ability to sign due to lack of consciousness or physical difficulties.

Study variables. Patient-level clinical information was extracted from the SEER and the Shanghai Tenth People's Hospital databases and included age at diagnosis, sex, ethnicity, marital status, tumor grade, histological type, SEER stage, TNM stage and number of lymph nodes removed. According to the status of lymph node metastasis, patients were divided into two groups: $\mathrm{N} 0$ and $\mathrm{N}$-positive $(\mathrm{N}+)$. $(\mathrm{N}+)$ included the three stages N1, N2 and N3. The clinicopathological characteristics included age at diagnosis $(<68,68-78$ and $>78$ years), sex (female and male), ethnicity (white, black and others) and marital status (married and unmarried). Tumor variables included SEER stages (localized, regional and distant), histological type (transitional cell carcinoma and other), $\mathrm{T}$ stage $(\mathrm{Ta}+\mathrm{Tis}, \mathrm{T} 1, \mathrm{~T} 2, \mathrm{~T} 3$ and $\mathrm{T} 4)$ and $\mathrm{M}$ stage (M0 and M1; cancer.gov/publications/dictionaries/cancer-terms/def/overall-survival). Tumor grades I, II, III and IV represented well-differentiated, moderately differentiated, poorly differentiated and undifferentiated tumors, respectively.

Statistical analysis. $\chi^{2}$ test was used to analyze the clinicopathological characteristics associated with N-stage. Kaplan-Meier curves and log-rank test were used to assess the overall survival (OS) time of patients with $\mathrm{BCa}$. Univariate and multivariate Cox regression analyses were used to determine the clinicopathological characteristics associated with OS. Multivariable Cox regression was used to analyze the patients' median survival time (MST) following stratification by N-stage in the SEER and Shanghai Tenth People's Hospital Urology databases. The stratification boundary for optimal number of LNDs was determined using X-tile software version 3.6.1 (21). SPSS (version 20.0; IBM Corp.) was used for all the statistical analyses. $\mathrm{P}<0.05$ was considered to indicate a statistically significant difference.

\section{Results}

Demographic and clinical characteristics of patients with $B C a$. A total of 17,730 and 158 patients with BCa were identified from the SEER database and Shanghai Tenth People's Hospital databases, respectively. For American N0 and N+ patients, the median number of dissected nodes was 11.0 [IQR (interquartile range) $=3.0-21.0]$ and $14.0(\mathrm{IQR}=8.0-23.0)$, respectively. The median number of LNDs for Chinese N0 and $\mathrm{N}+$ patients was $5.0(\mathrm{IQR}=2.0-7.0)$ and $5.0(\mathrm{IQR}=1.5-10.5)$, respectively. Table I presents the association between the clinicopathological characteristics and $\mathrm{N}$-stage of patients with $\mathrm{BCa}$ from the two aforementioned databases following $\chi^{2}$ test analysis. The age at diagnosis was stratified using X-tile software. The age of patients from the SEER and Shanghai Tenth People's Hospital database was divided into three groups as follows: $<68,68-78$ and $>78$ years (Fig. S1). The majority of patients with $\mathrm{BCa}$ were men $(75.0 \%$ American patients and $86.1 \%$ Chinese patients). The results from $\chi^{2}$ test demonstrated a significant association between $\mathrm{N}$-stage and numerous variables, including age at diagnosis $(\mathrm{P}<0.001)$, sex $(\mathrm{P}<0.001)$, ethnicity $(\mathrm{P}=0.020)$, marital status $(\mathrm{P}=0.002)$, SEER stage $(\mathrm{P}<0.001)$, tumor grade $(\mathrm{P}<0.001)$, histological type $(\mathrm{P}=0.009)$, T-stage $(\mathrm{P}<0.001)$ and $\mathrm{M}$-stage $(\mathrm{P}<0.001)$, in patients from the SEER database. In Chinese patients, $\mathrm{N}$-stage was associated with T-stage $(\mathrm{P}<0.001)$ and $\mathrm{M}$-stage $(\mathrm{P}<0.001$; Table I).

Effects of $N$-stage on the OS of patients who underwent RC. The effect of N-stage on the OS of patients who underwent RC from the two aforementioned databases was analyzed by Kaplan-Meier curves. The results demonstrated that the survival time of American patients from the SEER database was significantly different depending on the $\mathrm{N}$-stage $(\mathrm{P}<0.001$; Fig. 1A). In addition, a significant difference in the survival time of Chinese patients between the $\mathrm{N}$-stage subgroups was demonstrated $(\mathrm{P}<0.001$; Fig. 1B). These findings suggested that $\mathrm{N}$-stage was significantly associated with OS, and that the survival time of patients decreased as $\mathrm{N}$-stage increased.

Identification of risk factors for patients with BCa who underwent $R C$. Univariate and multivariate Cox regression were used to analyze the clinicopathological characteristics associated with the OS of patients with $\mathrm{BCa}$ who underwent $\mathrm{RC}$. The results from univariate Cox regression analysis demonstrated that age at diagnosis $(\mathrm{P}<0.001)$, sex $(\mathrm{P}<0.001)$, ethnicity $(\mathrm{P}<0.001)$, marital status $(\mathrm{P}<0.001)$, SEER stage $(\mathrm{P}<0.001)$, histological type $(\mathrm{P}<0.001)$, tumor grade $(\mathrm{P}<0.001)$, $\mathrm{T}$-stage $(\mathrm{P}<0.001$; TI: $\mathrm{P}=0.824), \mathrm{N}$-stage $(\mathrm{P}<0.001), \mathrm{M}$-stage $(\mathrm{P}<0.001)$ and number of removed lymph nodes $(\mathrm{P}<0.001)$ were significantly associated with the OS of American patients from the SEER database (Table II). The results from univariate Cox regression analysis demonstrated that age at diagnosis $(\mathrm{P}<0.001 ; 68-78$ : $\mathrm{P}=0.041)$, $\mathrm{N}$-stage $(\mathrm{P}<0.001)$, M-stage $(\mathrm{P}=0.003)$ and number of removed lymph nodes ( $\geq 8$ nodes: $\mathrm{P}=0.009$ ) were significantly associated with the OS of Chinese patients from the Shanghai 
Table I. Clinicopathological characteristics of patients with bladder cancer stratified by N-stage in the SEER and Shanghai Tenth People's Hospital Urology databases.

A, SEER database

\begin{tabular}{|c|c|c|c|c|}
\hline & & No & $\mathrm{N}+$ & \\
\hline Characteristic & All patients, n (\%) & Number (\%) & Number (\%) & P-value \\
\hline Total & 17,730 & $13,421(75.7)$ & $4,309(24.3)$ & \\
\hline Age at diagnosis, years & & & & $<0.001$ \\
\hline$<68$ & $8,279(46.7)$ & $6,083(73.5)$ & $2,196(26.5)$ & \\
\hline $68-78$ & $6,567(37.0)$ & $5,119(78.0)$ & $1,448(22.0)$ & \\
\hline$>78$ & $2,884(16.3)$ & $2,219(76.9)$ & $665(23.1)$ & \\
\hline Sex & & & & $<0.001$ \\
\hline Female & $4,431(25.0)$ & $3,257(73.5)$ & $1,174(26.5)$ & \\
\hline Male & $13,299(75.0)$ & $10,164(76.4)$ & $3,135(23.6)$ & \\
\hline Ethnicity & & & & 0.020 \\
\hline White & $15,722(88.7)$ & $11,932(75.9)$ & $3,790(24.1)$ & \\
\hline Black & $308(6.3)$ & $802(72.3)$ & $308(27.7)$ & \\
\hline Other & $211(5.1)$ & $687(76.5)$ & $211(23.5)$ & \\
\hline Marital status & & & & 0.002 \\
\hline Yes & $11,192(63.1)$ & $8,558(76.5)$ & $2,634(23.5)$ & \\
\hline No & $6,538(36.9)$ & $4,863(74.4)$ & $1,675(25.6)$ & \\
\hline SEER stage & & & & $<0.001$ \\
\hline Localized & $2,432(13.7)$ & $2,432(100.0)$ & $0(0.0)$ & \\
\hline Regional & $14,045(79.2)$ & $10,436(74.3)$ & $3,609(25.7)$ & \\
\hline Distant & $1,253(7.1)$ & $553(44.1)$ & $700(3.9)$ & \\
\hline Grade & & & & $<0.001$ \\
\hline $\mathrm{I}$ & $183(1.0)$ & $167(91.3)$ & $16(8.7)$ & \\
\hline II & $889(5.0)$ & $758(85.3)$ & $131(14.7)$ & \\
\hline III & $5,090(28.7)$ & $3,751(73.7)$ & $1,339(26.3)$ & \\
\hline IV & $10,545(59.5)$ & $7,896(74.9)$ & $2,649(25.1)$ & \\
\hline Unknown & $1,023(5.8)$ & $849(83.0)$ & $174(17.0)$ & \\
\hline Histological type & & & & 0.009 \\
\hline Transitional cell carcinoma & $16,014(90.3)$ & $12,166(76.0)$ & $3,848(24.0)$ & \\
\hline Others & $1,716(9.7)$ & $1,255(73.1)$ & $461(26.9)$ & \\
\hline T-stage ${ }^{a}$ & & & & $<0.001$ \\
\hline $\mathrm{Ta}+\mathrm{Tis}$ & $495(2.8)$ & $494(99.8)$ & $1(0.2)$ & \\
\hline $\mathrm{T} 1$ & 2,067 (11.7) & $1,974(95.5)$ & $93(4.5)$ & \\
\hline $\mathrm{T} 2$ & $6,617(37.3)$ & $5,799(87.6)$ & $818(12.4)$ & \\
\hline $\mathrm{T} 3$ & $5,452(30.8)$ & $3,481(63.8)$ & $1,971(36.2)$ & \\
\hline $\mathrm{T} 4$ & $3,099(17.5)$ & $1,673(54.0)$ & $1,426(46.0)$ & \\
\hline M-stage ${ }^{a}$ & & & & $<0.001$ \\
\hline M0 & $16,874(95.2)$ & $13,106(77.7)$ & $3,768(22.3)$ & \\
\hline M1 & $856(4.8)$ & $315(36.8)$ & $541(63.2)$ & \\
\hline Removed lymph nodes & & & & 0.810 \\
\hline Mean & 15.1 & 14.3 & 17.6 & \\
\hline Median & 11.0 & 11.0 & 14.0 & \\
\hline IQR & $4.0-21.0$ & $3.0-21.0$ & $8.0-23.0$ & \\
\hline
\end{tabular}


Table I. Continued.

B, Shanghai Tenth People's Hospital Urology database

\begin{tabular}{|c|c|c|c|c|}
\hline & & No & $\mathrm{N}+$ & \\
\hline Characteristic & All patients, n (\%) & Number $(\%)$ & Number $(\%)$ & P-value \\
\hline Total & 158 & $125(79.1)$ & 33 (20.9) & \\
\hline Age at diagnosis, years & & & & 0.969 \\
\hline$<68$ & $91(57.6)$ & $72(79.1)$ & $19(20.9)$ & \\
\hline $68-78$ & $46(29.1)$ & $36(78.3)$ & $10(21.7)$ & \\
\hline$>78$ & $21(13.3)$ & $17(81.0)$ & $4(19.0)$ & \\
\hline Sex & & & & 0.819 \\
\hline Female & $22(13.9)$ & $17(77.3)$ & $5(22.7)$ & \\
\hline Male & $136(86.1)$ & $108(79.4)$ & $28(20.6)$ & \\
\hline T-stage $^{\mathrm{a}}$ & & & & $<0.001$ \\
\hline $\mathrm{Ta}+\mathrm{Tis}$ & $6(4.8)$ & $6(100.0)$ & $0(0.0)$ & \\
\hline $\mathrm{T} 1$ & $61(38.6)$ & $56(91.8)$ & $5(8.2)$ & \\
\hline $\mathrm{T} 2$ & $29(18.4)$ & $27(93.1)$ & $2(6.9)$ & \\
\hline T3 & $31(19.6)$ & $22(71.0)$ & $9(29.0)$ & \\
\hline $\mathrm{T} 4$ & $31(19.6)$ & $14(45.2)$ & $17(54.8)$ & \\
\hline M-stage ${ }^{a}$ & & & & $<0.001$ \\
\hline M0 & $150(94.9)$ & $123(82.0)$ & $27(18.0)$ & \\
\hline M1 & $8(5.1)$ & $2(25.0)$ & $6(75.0)$ & \\
\hline Removed lymph nodes & & & & $<0.001$ \\
\hline Mean & 5.2 & 4.9 & 6.3 & \\
\hline Median & 5.0 & 5.0 & 5.0 & \\
\hline IQR & $2.0-7.3$ & $2.0-7.0$ & $1.5-10.5$ & \\
\hline
\end{tabular}

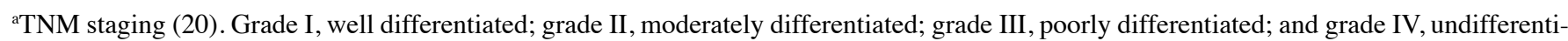
ated. Percentages may not total 100 due to approximation of decimal values. IQR, interquartile range; SEER, Surveillance, Epidemiology and End Results; T, tumor; N, node; M, metastasis.


Figure 1. Kaplan-Meier survival curves according to N-stage (N0, N1, N2 and N3) in (A) American patients with BCa from the Surveillance, Epidemiology and End Results database and (B) Chinese patients with BCa from the Urology database of the Shanghai Tenth People's Hospital. BCa, bladder cancer; N, node. 
Table II. Univariate and multivariate Cox regression analyses predicting the overall survival of patients with bladder cancer from the SEER database.

\begin{tabular}{|c|c|c|c|c|}
\hline \multirow[b]{2}{*}{ Characteristic } & \multicolumn{2}{|c|}{ Univariate Cox regression } & \multicolumn{2}{|c|}{ Multivariate Cox regression } \\
\hline & Hazard ratio $(95 \% \mathrm{CI})$ & P-value & Hazard ratio $(95 \% \mathrm{CI})$ & P-value \\
\hline \multicolumn{5}{|l|}{ Age at diagnosis, years } \\
\hline$<68$ & Reference & & Reference & \\
\hline $68-78$ & $1.37(1.31-1.43)$ & $<0.001$ & $1.39(1.33-1.46)$ & $<0.001$ \\
\hline$>78$ & $2.09(1.98-2.21)$ & $<0.001$ & $1.98(1.87-2.09)$ & $<0.001$ \\
\hline \multicolumn{5}{|l|}{ Sex } \\
\hline Female & Reference & & Reference & \\
\hline Male & $0.88(0.84-0.92)$ & $<0.001$ & - & 0.198 \\
\hline \multicolumn{5}{|l|}{ Ethnicity } \\
\hline White & Reference & & Reference & \\
\hline Black & $1.33(1.23-1.44)$ & $<0.001$ & $1.24(1.15-1.35)$ & $<0.001$ \\
\hline Other & $0.83(0.750 .92)$ & $<0.001$ & $0.81(0.73-0.90)$ & $<0.001$ \\
\hline \multicolumn{5}{|l|}{ Marital status } \\
\hline Yes & Reference & & Reference & \\
\hline No & $1.26(1.21-1.31)$ & $<0.001$ & $1.19(1.14-1.25)$ & $<0.001$ \\
\hline \multicolumn{5}{|l|}{ SEER stage } \\
\hline Localized & Reference & & Reference & \\
\hline Regional & $2.11(1.96-2.28)$ & $<0.001$ & $1.47(1.14-1.90)$ & 0.003 \\
\hline Distant & $6.34(5.77-6.98)$ & $<0.001$ & $2.72(2.09-3.54)$ & $<0.001$ \\
\hline \multicolumn{5}{|l|}{ Grade } \\
\hline I & Reference & & Reference & \\
\hline II & $1.48(1.16-1.89)$ & 0.002 & $1.26(0.99-1.67)$ & 0.065 \\
\hline III & $1.66(1.32-2.09)$ & $<0.001$ & $1.38(1.10-1.74)$ & 0.006 \\
\hline IV & $1.48(1.18-1.86)$ & 0.001 & $1.28(1.01-1.61)$ & 0.038 \\
\hline Unknown & $1.28(1.01-1.64)$ & 0.046 & $1.24(0.97-1.59)$ & 0.084 \\
\hline \multicolumn{5}{|l|}{ Histological type } \\
\hline Transitional cell carcinoma & Reference & & Reference & \\
\hline Others & $1.37(1.28-1.46)$ & $<0.001$ & $1.22(1.14-1.31)$ & $<0.001$ \\
\hline \multicolumn{5}{|l|}{ T-stage $\mathrm{e}^{\mathrm{a}}$} \\
\hline $\mathrm{Ta}+\mathrm{Tis}$ & Reference & & Reference & \\
\hline $\mathrm{T} 1$ & $1.02(0.86-1.21)$ & 0.824 & $1.04(0.87-1.25)$ & 0.646 \\
\hline $\mathrm{T} 2$ & $1.30(1.11-1.53)$ & 0.001 & $0.90(0.66-1.22)$ & 0.488 \\
\hline $\mathrm{T} 3$ & $2.84(2.43-3.34)$ & $<0.001$ & $1.65(1.22-2.24)$ & 0.001 \\
\hline $\mathrm{T} 4$ & $4.25(3.62-4.99)$ & $<0.001$ & $2.11(1.56-2.85)$ & $<0.001$ \\
\hline \multicolumn{5}{|l|}{ N-stage ${ }^{a}$} \\
\hline N0 & Reference & & Reference & \\
\hline $\mathrm{N}+$ & $2.41(2.30-2.51)$ & $<0.001$ & $1.85(1.76-1.94)$ & $<0.001$ \\
\hline \multicolumn{5}{|l|}{ M-stage ${ }^{a}$} \\
\hline M0 & Reference & & Reference & \\
\hline M1 & $3.12(2.88-3.38)$ & $<0.001$ & - & 0.113 \\
\hline \multicolumn{5}{|l|}{ Removed lymph nodes, no. } \\
\hline $6-12$ & $0.85(0.80-0.90)$ & $<0.001$ & $0.72(0.68-0.76)$ & $<0.001$ \\
\hline$\geq 13$ & $0.71(0.68-0.75)$ & $<0.001$ & $0.62(0.59-0.65)$ & $<0.001$ \\
\hline
\end{tabular}

Tenth People's Hospital Urology database (Table III). The results from multivariate Cox regression analysis demonstrated that only sex, T-stage and M-stage were not associated with the OS in both American and Chinese patients. 
Table III. Univariate and multivariate Cox regression analyses predicting the overall survival of patients with bladder cancer from the Shanghai Tenth People's Hospital Urology database.

\begin{tabular}{|c|c|c|c|c|}
\hline \multirow[b]{2}{*}{ Characteristic } & \multicolumn{2}{|c|}{ Univariate Cox regression } & \multicolumn{2}{|c|}{ Multivariate Cox regression } \\
\hline & Hazard ratio $(95 \% \mathrm{CI})$ & P-value & Hazard ratio $(95 \% \mathrm{CI})$ & P-value \\
\hline \multicolumn{5}{|c|}{ Age at diagnosis, years } \\
\hline$<68$ & Reference & & Reference & \\
\hline $68-78$ & $1.74(1.02-2.96)$ & 0.041 & $1.25(0.71-2.19)$ & 0.435 \\
\hline$>78$ & $3.04(1.66-5.56)$ & $<0.001$ & $3.60(1.84-7.05)$ & $<0.001$ \\
\hline \multicolumn{5}{|l|}{ Sex } \\
\hline Female & Reference & & Reference & \\
\hline Male & $0.85(0.46-1.58)$ & 0.600 & - & 0.236 \\
\hline \multicolumn{5}{|l|}{ T-stage ${ }^{a}$} \\
\hline $\mathrm{Ta}+\mathrm{Tis}$ & Reference & & Reference & \\
\hline $\mathrm{T} 1$ & $1.56(0.21-11.73)$ & 0.669 & $1.05(0.14-8.07)$ & 0.966 \\
\hline $\mathrm{T} 2$ & $2.83(0.37-21.93)$ & 0.320 & $1.77(0.22-14.12)$ & 0.592 \\
\hline $\mathrm{T} 3$ & $4.11(0.55-30.91)$ & 0.170 & $2.96(0.39-22.56)$ & 0.296 \\
\hline $\mathrm{T} 4$ & $7.53(1.02-55.56)$ & 0.048 & $4.74(0.60-37.22)$ & 0.139 \\
\hline \multicolumn{5}{|l|}{$\mathrm{N}$-stage $\mathrm{a}^{\mathrm{a}}$} \\
\hline No & Reference & & Reference & \\
\hline $\mathrm{N}+$ & $3.39(2.06-5.57)$ & $<0.001$ & $2.40(1.33-4.35)$ & 0.004 \\
\hline \multicolumn{5}{|l|}{ M-stage ${ }^{a}$} \\
\hline M0 & Reference & & Reference & \\
\hline M1 & $3.33(1.52-7.28)$ & 0.003 & - & 0.591 \\
\hline $\begin{array}{l}\text { Removed lymp } \\
\leq 1\end{array}$ & Reference & & Reference & \\
\hline $2-7$ & $0.73(0.44-1.22)$ & 0.236 & $0.66(0.39-1.13)$ & 0.131 \\
\hline$\geq 8$ & $0.36(0.17-0.77)$ & 0.009 & $0.27(0.12-0.62)$ & 0.002 \\
\hline
\end{tabular}

${ }^{a}$ TNM staging (20). CI, confidence interval; T, tumor; N, node; M, metastasis.

The number of LNDs was stratified using X-tile software (21). The number of LNDs in American patients from the SEER database was divided as follows: $\leq 5,6-12$ and $\geq 13$ nodes (Fig. 2A). The number of LNDs in Chinese patients from the Shanghai Tenth People's Hospital database was divided as follows: $\leq 1,2-7$ and $\geq 8$ nodes (Fig. 3A). The number of LNDs was also stratified according to patients with $\mathrm{BCa}$ patients with different $\mathrm{N}$ stages. American patients with BCa with N0-stage was classified as: $\leq 3,4-10$ and $\geq 11$ nodes (Fig. $2 \mathrm{~B}$ ); the N+-stage patients as: $\leq 6,7-17$ and $\geq 18$ nodes (Fig. 2C). Simultaneously, the same stratified analysis was performed on data from Chinese patients with $\mathrm{BCa}$. Results were as follows: $\leq 1,2-6$ and $\geq 7$ nodes for N0-stage (Fig. 3B); $\leq 3,4-7$ and $\geq 8$ nodes for N+-stage (Fig. 3C).

The results from multivariate Cox regression analysis demonstrated that the number of LNDs [6-12 vs. $\leq 5$ nodes, hazard ratio $(\mathrm{HR})=0.72,95 \%$ confidence interval $(\mathrm{CI})=0.68-0.76 ; \mathrm{P}<0.001 ; \geq 13$ vs. $\leq 5$ nodes, $\mathrm{HR}=0.62$, $95 \% \mathrm{CI}=0.59-0.65, \mathrm{P}<0.001]$ was significantly associated with the OS of American patients from the SEER database (Table II). The results from multivariate Cox regression analysis demonstrated that the number of LNDs ( $\geq 8$ vs. $\leq 1$ nodes, $\mathrm{HR}=0.27,95 \% \mathrm{CI}=0.12-0.62, \mathrm{P}=0.002)$ was significantly associated with the OS of Chinese patients from the Shanghai Tenth People's Hospital Urology database (Table III). These findings suggested that higher number of LNDs was a protective factor for patients with $\mathrm{BCa}$ who underwent RC.

Effect of LND on the MST of patients with BCa according to $N$-stage. Patients from the two aforementioned databases were divided into two subgroups according to $\mathrm{N}$-stage, namely N0 and $\mathrm{N}+$. The difference between the number of LNDs and the prognosis of patients with $\mathrm{BCa}$ who underwent $\mathrm{RC}$ according to the $\mathrm{N}$-stage subgroup was evaluated (Table IV). The number of LNDs in N0 and N+ patients was stratified using X-tile software. The results demonstrated that LND [N0:4-10 vs. $\leq 3$ nodes, $\mathrm{HR}=0.72,95 \% \mathrm{CI}=0.68-0.77, \mathrm{P}<0.001 ; \geq 11$ vs. $\leq 3$ nodes, $\mathrm{HR}=0.58,95 \% \mathrm{CI}=0.54-0.61, \mathrm{P}<0.001 ; \mathrm{N}+7-17$ vs. $\leq 6$ nodes, $\mathrm{HR}=0.75,95 \% \mathrm{CI}=0.68-0.82, \mathrm{P}<0.001 ; \geq 18 \leq 6$ nodes, $\mathrm{HR}=0.62,95 \% \mathrm{CI}=0.56-0.68, \mathrm{P}<0.001]$ remained an independent prognostic factor for the MST of American patients with BCa at different $\mathrm{N}$-stages (Table IV). Among N0 Chinese patients, those in the $\geq 7$ nodes group had increased MST compared with that of patients in the $\leq 1$ node group (43.0 vs. 30.5 months; $P=0.226$; failed to calculate HR and 95\% CI because there was no difference in statistical analysis; 

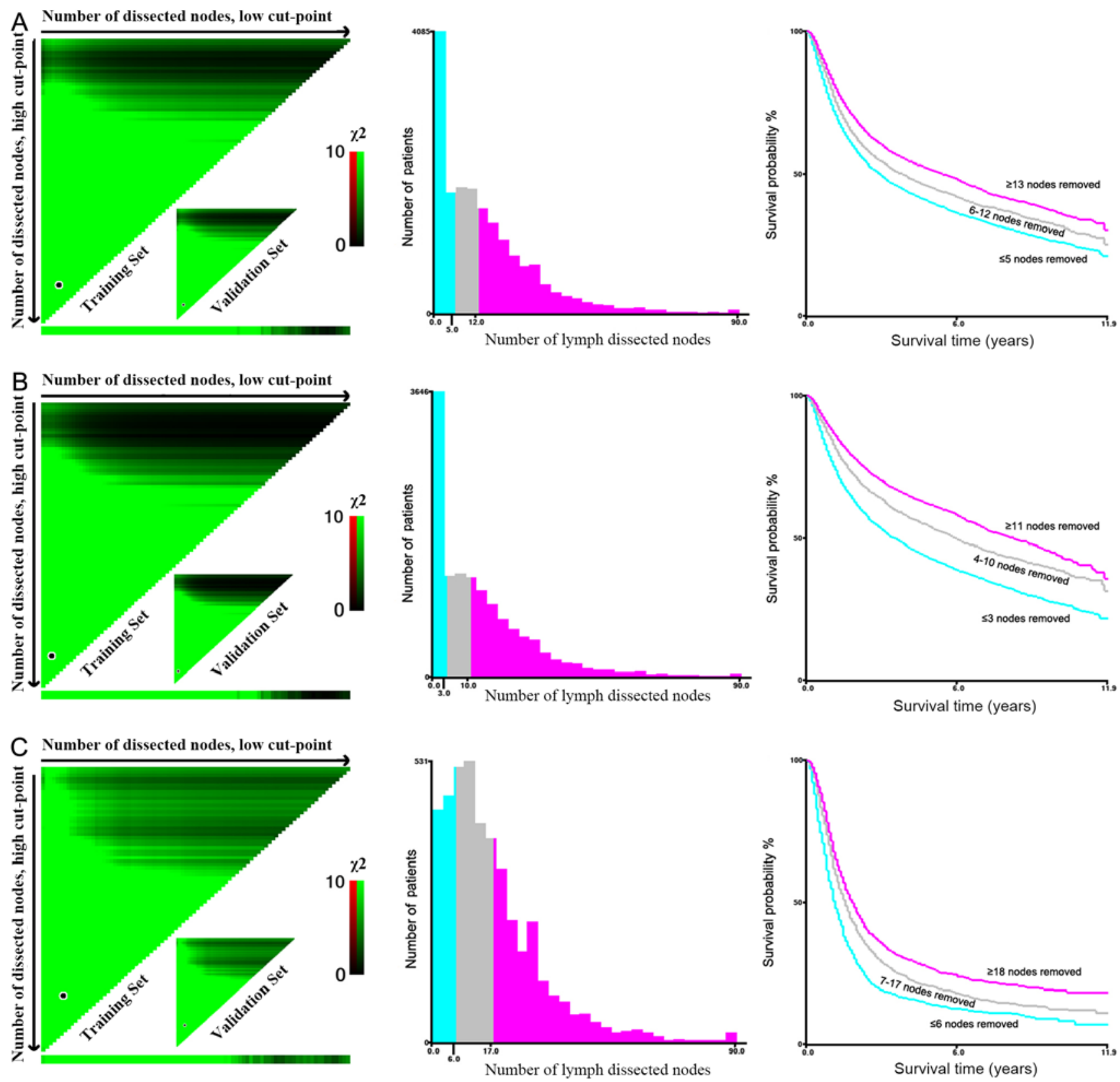

Figure 2. Estimation of the cut-off value for the number of lymph node dissection stratification determined by X-tile software (21). Increasing the number of LNDs will promote OS, regardless of $\mathrm{N}$-stage. Pink represents patients who had $\geq 13$ nodes removed, gray represents patients who had 6-12 nodes removed and blue represents patients who had $\leq 5$ nodes removed. (A) All American patients, (B) American patients with N0 stage and (C) American patients with N+ stage. N, node.

Table IV). In addition, $\mathrm{N}+$ Chinese patients in the $\geq 8$ nodes group had a longer MST compared with that of patients in the $\leq 3$ nodes group ( 23.5 vs. 10.5 months; HR=0.19, 95\% CI=0.07-0.56; P=0.003; Table IV). Furthermore, regarding N0 American patients, those in the $\geq 11$ nodes group had a longer MST compared with that of patients in the $\leq 3$ nodes group (MST, 34.0 vs. 27.0 months; HR=0.58, 95\% CI=0.54-0.61; $\mathrm{P}<0.001$; Table IV). Among the American $\mathrm{N}+$ patients, those in the $\geq 18$ nodes group had a longer MST compared with that of patients in the $\leq 6$ nodes group (MST, 17.0 vs. 12.0 months; $\mathrm{HR}=0.62,95 \% \mathrm{CI}=0.56-0.68 ; \mathrm{P}<0.001$; Table IV). For Chinese patients, only $\geq 8$ nodes was significant for MST in N+-stage patients (HR=0.19, 95\% CI=0.07-0.56, $\mathrm{P}=0.003$; Table IV). In addition, the number of LNDs in each $\mathrm{N}$-stage was generally higher in American patients (Table IV).

\section{Discussion}

The present study analyzed data from American and Chinese patients with $\mathrm{BCa}$, and demonstrated that LND was an independent prognostic factor for OS. Furthermore, increased number of LNDs was associated with increased survival time. These results were similar to those from previous studies, which reported that extended LND can increase the survival time of patients with $\mathrm{BCa}$ who underwent $\mathrm{RC}$, and reduce the recurrence rate $(22,23)$. Numerous studies reported these results in American patients $(24,25)$, although no comparison has been made to date with Chinese patients.

At present, it is usual to divide the LND during RC in patients with $\mathrm{BCa}$ into four grades according to the size of the clearing scope as follows: Limited LND, standard LND, 

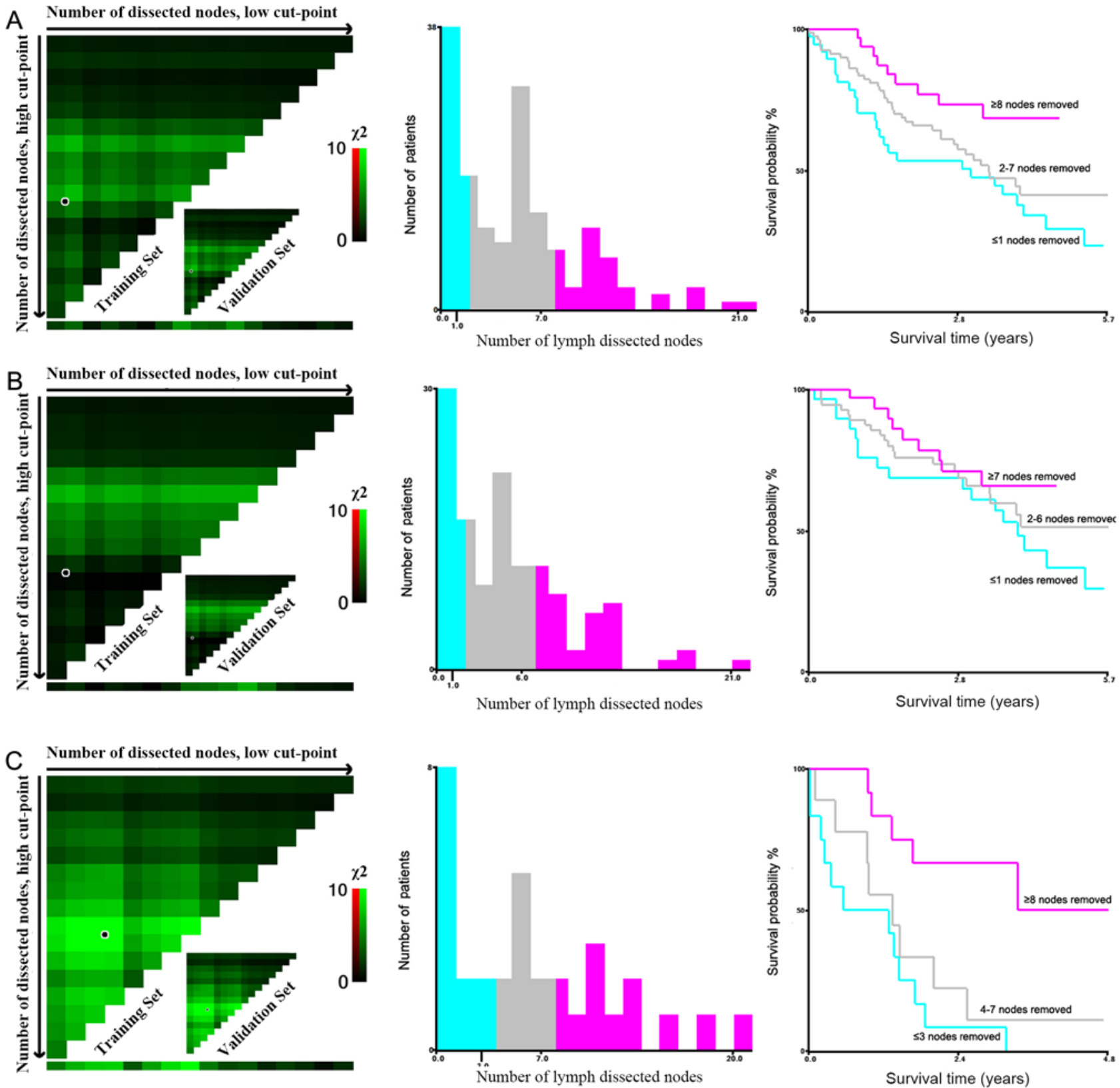

Figure 3. Estimation of the cut-off value for the number of lymph node dissection stratification determined by X-tile software (21). Pink represents patients who had $\geq 13$ nodes removed, gray represents patients who had 6-12 nodes removed and blue represents patients who had $\leq 5$ nodes removed. (A) All Chinese patients, (B) Chinese patients with N0 stage and (C) Chinese patients with N+ stage. N, node.

extended LND and super-extended LND (15). Previous studies reported that expanding the extent and number of LNDs has a crucial impact on the prognostic significance, not only for lymph node-positive patients but also for the postoperative prognosis of lymph node-negative patients $(26,27)$. In addition, it was reported that LND might be an independent prognostic factor for the prognosis of patients with $\mathrm{BCa}$, since extended LND can reduce micrometastasis (28). Dhar et al (29) demonstrated that patients with extended LND have a higher lymph node positivity rate (extended lymph node dissection (26\%) vs. limited lymph node dissection (13\%). Abol-Enein et al (30) demonstrated that the 5 year disease-free survival rate of patients undergoing extended LND in a non-randomized prospective cohort study was $66.6 \%$ (extended lymphadenectomy) vs. $54.7 \%$ (standard lymphadenectomy). In addition, extended LND can also reduce the probability of pelvic organ metastasis $(27,31)$. Although numerous studies reported this result, some controversies exist. Gschwend et al (18) demonstrated in a prospective randomized trial that extended LND failed to present a significant advantage over limited LND regarding the recurrence-free survival, cancer-specific survival and OS of patients with $\mathrm{BCa}$. Whether LND may be considered as an independent prognostic factor for $\mathrm{BCa}$ remains unclear.

The present study analyzed data from 17,730 American patients with BCa from the SEER database. For comparative analysis, the clinical information of 158 Chinese patients with $\mathrm{BCa}$ was collected from the center database of the Shanghai Tenth People's Hospital. One experienced senior surgeon performed operation on all Chinese patients in order to ensure reliable and convincing data, and to avoid unreliable data 
Table IV. Multivariate Cox regression analyses for patients stratified by N-stage in the SEER and Shanghai Tenth People's Hospital Urology databases.

A, SEER database

\begin{tabular}{|c|c|c|c|}
\hline Characteristic & MST, months & Hazard ratio $(95 \% \mathrm{CI})$ & P-value \\
\hline \multicolumn{4}{|l|}{$\mathrm{NO}^{\mathrm{a}}$} \\
\hline \multicolumn{4}{|c|}{ Removed lymph nodes, no. } \\
\hline$\leq 3$ & 27.0 & Reference & \\
\hline $4-10$ & 33.0 & $0.72(0.68-0.77)$ & $<0.001$ \\
\hline$\geq 11$ & 34.0 & $0.58(0.54-0.61)$ & $<0.001$ \\
\hline \multicolumn{4}{|l|}{$\mathrm{N}+{ }^{\mathrm{a}}$} \\
\hline \multicolumn{4}{|c|}{ Removed lymph nodes, no. } \\
\hline$\leq 6$ & 12.0 & Reference & \\
\hline $7-17$ & 15.0 & $0.75(0.68-0.82)$ & $<0.001$ \\
\hline$\geq 18$ & 17.0 & $0.62(0.56-0.68)$ & $<0.001$ \\
\hline
\end{tabular}

B, Shanghai Tenth People's Hospital Urology database

\begin{tabular}{|c|c|c|c|}
\hline Characteristic & MST, months & Hazard ratio $(95 \% \mathrm{CI})$ & P-value \\
\hline \multicolumn{4}{|l|}{$\mathrm{NO}^{\mathrm{a}}$} \\
\hline \multicolumn{4}{|c|}{ Removed lymph nodes, no. } \\
\hline $2-6$ & 34.0 & - & 0.919 \\
\hline$\geq 7$ & 43.0 & - & 0.226 \\
\hline \multicolumn{4}{|l|}{$\mathrm{N}+{ }^{\mathrm{a}}$} \\
\hline \multicolumn{4}{|c|}{ Removed lymph nodes, no. } \\
\hline$\leq 3$ & 10.5 & Reference & \\
\hline $4-7$ & 16.0 & $0.59(0.24-1.48)$ & 0.262 \\
\hline$\geq 8$ & 23.5 & $0.19(0.07-0.56)$ & 0.003 \\
\hline
\end{tabular}

${ }^{a}$ TNM staging (20). CI, confidence interval; MST, median survival time; SEER, Surveillance, Epidemiology and End Results; N, node.

deviations from different surgeons. The result from this study demonstrated that $\mathrm{N}$-stage may be considered as a risk factor for the OS of both American and Chinese patients. In addition, the OS of $\mathrm{N}+$ patients was significantly lower compared with that of N0 patients in the two populations. In addition, the survival time was significantly prolonged as the number of LNDs increased for different $\mathrm{N}$-stage patients form the two different populations.

In the present study, the results from multivariate Cox regression analysis demonstrated that the number of LND was correlated with patient's OS time and directly proportional to the postoperative survival benefit. The increased number of LNDs reduced the likelihood of potential lymph node metastases. This increased the possibility of prolonged survival time after surgery. In addition, the median number of LNDs in American patients was significantly higher compared with that in Chinese patients (11.0 vs. 5.0 nodes). These findings suggested that the removal of a larger quantity of lymph nodes increased the patients' survival. These results were consistent with those from previous reports $(32,33)$. Furthermore, it has been reported that extended LND can reduce the risk of recurrence and tumor burden (34). Extended LND can provide survival benefit in patients and facilitate the collection of other prognostic information, including tumor burden, lymph node density and lymph node extracapsular infiltration $(9,10,17)$. The present study also demonstrated that the number of LNDs in Chinese patients was generally low compared with that in American patients. It could therefore be recommended that surgeons expand the range of LND in order to increase the number of LNDs during radical resection in patients with $\mathrm{BCa}$. This may increase the patients' OS time and reduce the disease recurrence rate.

Stratified analysis demonstrated that, different LND groups could achieve better survival benefits compared to $\leq 3$ groups (N0-stage) and $\leq 6$ groups (N+stage) for American patients with different $\mathrm{N}$-stage $(\mathrm{P}<0.001)$. For Chinese patients, only the $\geq 8$ nodes group had a longer MST compared with the $\leq 6$ groups in $\mathrm{N}+$ stage $(\mathrm{P}=0.003)$. The minimum number of LNDs according to data from the Shanghai Tenth People's Hospital database was only 1 node. The median LND for American patients was more than twice the median LND for Chinese patients. In addition, the median LND in Chinese patients was $\leq 6$ nodes, which the number in SEER database analysis presented a worse prognosis 
and a shorter OS time in American patients. These observations may be due to the lack of universal robot surgery in Shanghai Tenth People's Hospital and inaccurate postoperative pathological lymph node count. The lack of awareness by our institution (Department of Urology, Shanghai Tenth People's Hospital) about the prognostic value of LND may explain these results.

This study presented some limitations. Firstly, the SEER database is a retrospective dataset with limitations inherent to retrospective research, for example retrospective analysis is prone to selection and recall bias (35). Moreover, the data from the SEER database were collected by different cancer centers and, depending on the statistician, there may be selection bias. Secondly, data from Chinese patients were only collected from Shanghai Tenth People's Hospital and may therefore not be representative of all Chinese patients with $\mathrm{BCa}$. Thirdly, information of only 158 Chinese patients was collected, which is a small sample size. Further multicenter prospective clinical trials are therefore required.

In conclusion, the present study demonstrated that the number of LNDs was an independent prognostic factor for the survival of patients with $\mathrm{BCa}$. In addition, an increased number of LNDs had a protective effect on the OS of patients with BCa. Furthermore, the number of LNDs in Chinese patients was lower compared with that in American patients. The number of LNDs should therefore be increased when treating patients with $\mathrm{BCa}$ in China.

\section{Acknowledgements}

Not applicable.

\section{Funding}

This work was supported by the National Natural Science Foundation of China (grant no. 81870517).

\section{Availability of data and materials}

The datasets used and/or analyzed during the current study are available from the corresponding author on reasonable request.

\section{Authors' contributions}

$\mathrm{KW}, \mathrm{HS}, \mathrm{WM}$ and BP were involved in the study conception and design. LY, WL and JX obtaining and performing relevant statistical analysis from two databases. KW, GW and DF were involved in data analysis and interpretation. KW and $\mathrm{BP}$ wrote the manuscript.

\section{Ethics approval and consent to participate}

The study protocol was approved by The Biomedical Ethics Committee of the Tenth People's Hospital in Shanghai. Written informed consent was obtained from the patients or their next of kin if the patient did not have the ability to sign due to lack of consciousness or physical difficulties. All authors read and approved the final manuscript.

\section{Patient consent for publication}

Written informed consent was obtained from each patient prior to publication.

\section{Competing interests}

The authors declare that they have no competing interests.

\section{References}

1. Zhang ZF, Zhang HR, Zhang QY, Lai SY, Feng YZ, Zhou Y, Zheng SR, Shi R and Zhou JY: High expression of TMEM40 is associated with the malignant behavior and tumorigenesis in bladder cancer. J Transl Med 16: 9, 2018.

2. Siegel RL, Miller KD and Jemal A: Cancer statistics, 2018. CA Cancer J Clin 68: 7-30, 2018.

3. Czerniak B, Dinney C and McConkey D: Origins of bladder cancer. Ann Rev Pathol 11: 149-174, 2016.

4. Burger M, Catto JW, Dalbagni G, Grossman HB, Herr H, Karakiewicz P, Kassouf W, Kiemeney LA, La Vecchia C, Shariat S and Lotan Y: Epidemiology and risk factors of urothelial bladder cancer. Eur Urol 63: 234-241, 2013.

5. Mao W, Huang X, Wang L, Zhang Z, Liu M, Li Y, Luo M, Yao X, Fan J and Geng J: Circular RNA hsa_circ_0068871 regulates FGFR3 expression and activates STAT3 by targeting miR-181a-5p to promote bladder cancer progression. J Exp Clin Cancer Res 38: 169, 2019.

6. Babjuk M, Oosterlinck W, Sylvester R, Kaasinen E, Böhle A, Palou-Redorta J and European Association of Urology (EAU): EAU guidelines on non-muscle-invasive urothelial carcinoma of the bladder. Eur Urol 54: 303-314, 2008.

7. Gupta NP, Goel R, Hemal AK, Dogra PN, Seth A, Aron M, Kumar R and Ansari MS: Radical cystectomy in septuagenarian patients with bladder cancer. Int Urol Nephrol 36: 353-358, 2004.

8. Alfred Witjes J, Lebret T, Comperat EM, Cowan NC, De Santis M, Bruins HM, Hernández V, Espinós EL, Dunn J, Rouanne M, et al: Updated 2016 EAU guidelines on muscle-invasive and metastatic bladder cancer. Eur Urol 71: 462-475, 2017.

9. Konety BR, Joslyn SA and O'Donnell MA: Extent of pelvic lymphadenectomy and its impact on outcome in patients diagnosed with bladder cancer: Analysis of data from the surveillance, epidemiology and end results program data base. J Urol 169: 946-950, 2003.

10. Siemens DR, Mackillop WJ, Peng Y, Wei X, Berman D and Booth CM: Lymph node counts are valid indicators of the quality of surgical care in bladder cancer: A population-based study. Urol Oncol 33: e415-e423, 2015.

11. May M, Herrmann E, Bolenz C, Tiemann A, Brookman-May S, Fritsche HM, Burger M, Buchner A, Gratzke C, Wülfing C, et al: Lymph node density affects cancer-specific survival in patients with lymph node-positive urothelial bladder cancer following radical cystectomy. Eur Urol 59: 712-718, 2011.

12. Herr H, Lee C, Chang S, Lerner S and Bladder Cancer Collaborative G: Standardization of radical cystectomy and pelvic lymph node dissection for bladder cancer: A collaborative group report. J Urol 171: 1823-1828, 2004.

13. Hedgepeth RC, Zhang Y, Skolarus TA and Hollenbeck BK: Variation in use of lymph node dissection during radical cystectomy for bladder cancer. Urology 77: 772011, 2011.

14. Simone G, Papalia R, Ferriero M, Guaglianone S, Castelli E, Collura D, Muto G and Gallucci M: Stage-specific impact of extended versus standard pelvic lymph node dissection in radical cystectomy. Int J Urol 20: 390-397, 2013.

15. Bruins HM,Veskimae E,HernandezV,Imamura M,NeubergerMM, Dahm P, Stewart F, Lam TB, N'Dow J, van der Heijden AG, et al: The impact of the extent of lymphadenectomy on oncologic outcomes in patients undergoing radical cystectomy for bladder cancer: A systematic review. Eur Urol 66: 1065-1077, 2014.

16. Cole AP, Dalela D, Hanske J, Mullane SA, Choueiri TK, Meyer CP, Nguyen PL, Menon M, Kibel AS, Preston MA, et al: Temporal trends in receipt of adequate lymphadenectomy in bladder cancer 1988 to 2010. Urol Oncol 33: e509-e517, 2015.

17. Maruf M, Sidana A, Purnell S, Jain AL, Brancato SJ and Agarwal PK: Lymph node dissection during radical cystectomy following prior radiation therapy: Results from the SEER database. Int Urol Nephrol 50: 257-262, 2018.

18. Gschwend JE, Heck MM, Lehmann J, Rübben H, Albers P, Wolff JM, Frohneberg D, de Geeter P, Heidenreich A, Kälble T, et al: Extended versus limited lymph node dissection in bladder cancer patients undergoing radical cystectomy: Survival results from a prospective, randomized trial. Eur Urol 75: 604-611, 2019. 
19. Mao W, Ma B, Huang X, Gu S, Luo M, Fan J and Geng J: Which treatment is best for patients with AJCC stage IV bladder cancer? Int Urol Nephrol 51: 1145-1156, 2019.

20. Compton CC, Byrd DR, Garciaaguilar J, Kurtzman SH and Olawaiye A: AJCC Cancer Staging Atlas. Springer, Berlin, 2012

21. Camp RL, Dolled-Filhart M and Rimm DL: X-tile: A new bio-informatics tool for biomarker assessment and outcome-based cut-point optimization. Clin Cancer Res 10: 7252-7259, 2004.

22. Leissner J, Hohenfellner R, Thuroff JW and Wolf HK: Lymphadenectomy in patients with transitional cell carcinoma of the urinary bladder; significance for staging and prognosis. BJU Int 85: 817-823, 2000.

23. von Landenberg N, Speed JM, Cole AP, Seisen T, Lipsitz SR, Gild P, Menon M, Kibel AS, Roghmann F, Noldus J, et al: Impact of adequate pelvic lymph node dissection on overall survival after radical cystectomy: A stratified analysis by clinical stage and receipt of neoadjuvant chemotherap. Urol Oncol 36: e13-e78, 2018.

24. Stabile A, Muttin F, Zamboni S, Moschini M, Gandaglia G, Fossati N, Dell'Oglio P, Capitanio U, Cucchiara V, Mazzone E, et al: Therapeutic approaches for lymph node involvement in prostate, bladder and kidney cancer. Expert Rev Anticancer Ther 19: 739-755, 2019.

25. Lee EK, Herr HW, Dickstein RJ, Kassouf W, Munsell MF, Grossman HB, Dinney CP and Kamat AM: Lymph node density for patient counselling about prognosis and for designing clinical trials of adjuvant therapies after radical cystectomy. BJU Int 110: E590-E595, 2012.

26. Sharma M, Goto T, Yang $\mathrm{Z}$ and Miyamoto $\mathrm{H}$ : The impact of perivesical lymph node metastasis on clinical outcomes of bladder cancer patients undergoing radical cystectomy. BMC Urol 19: 77, 2019.

27. Perera M, McGrath S, Sengupta S, Crozier J, Bolton D and Lawrentschuk N: Pelvic lymph node dissection during radical cystectomy for muscle-invasive bladder cancer. Nat Rev Urol 15: 686-692, 2018

28. Herr HW, Bochner BH, Dalbagni G, Donat SM, Reuter VE and Bajorin DF: Impact of the number of lymph nodes retrieved on outcome in patients with muscle invasive bladder cancer. J Urol 167: 1295-1298, 2002.
29. Dhar NB, Klein EA, Reuther AM, Thalmann GN, Madersbacher S and Studer UE: Outcome after radical cystectomy with limited or extended pelvic lymph node dissection. J Urol 179: 873-878, 2008.

30. Abol-Enein H, Tilki D, Mosbah A, El-Baz M, Shokeir A, Nabeeh A and Ghoneim MA: Does the extent of lymphadenectomy in radical cystectomy for bladder cancer influence disease-free survival? A prospective single-center study. Eur Urol 60: 572-577, 2011.

31. Poulsen AL, Horn T and Steven K: Radical cystectomy: Extending the limits of pelvic lymph node dissection improves survival for patients with bladder cancer confined to the bladder wall. J Urol 160: 2015-2019, 1998.

32. Koppie TM, Vickers AJ, Vora K, Dalbagni G and Bochner BH: Standardization of pelvic lymphadenectomy performed at radical cystectomy: Can we establish a minimum number of lymph nodes that should be removed? Cancer 107: 2368-2374, 2006.

33. Herr HW: Extent of surgery and pathology evaluation has an impact on bladder cancer outcomes after radical cystectomy. Urology 61: 105-108, 2003.

34. Masson-Lecomte A, Vordos D, Hoznek A, Yiou R, Allory Y, Abbou CC, de la Taille A and Salomon L: External validation of extranodal extension and lymph node density as predictors of survival in node-positive bladder cancer after radical cystectomy. Ann Surg Oncol 20: 1389-1394, 2013.

35. Crump K: The potential effects of recall bias and selection bias on the epidemiological evidence for the carcinogenicity of glyphosate. Risk Anal 30: 13440, 2019. 